\title{
Dimethylhydrazine model is not appropriate for evaluating effect of ethanol on colorectal cancer
}

\author{
M. Perše and A. Cerar \\ Institute of Pathology. Medical Experimental Centre. Medical Faculty. University of Ljubljana. Korytkova, Slovenia
}

\begin{abstract}
RESUMEN
Se ha observado que el modelo de la 1,2-dimetilhidrazina (DMH) en la rata es un valioso modelo animal de cáncer colorrectal. Debido a su parecido morfológico con el cáncer colorrectal humano, el modelo de la $\mathrm{DMH}$ en la rata se ha empleado para conseguir información acerca de la histología y la bioquímica del desarrollo tumoral, además de sobre los factores que retrasan o potencian la tumorigénesis. No obstante, se ha visto que el modelo de la DMH tiene sus limitaciones, lo que lleva a preguntarse si están justificados, desde el punto de vista ético, los experimentos que evalúan el efecto del etanol sobre este modelo. En este documento, los autores resumen los resultados experimentales que evalúan el efecto del consumo de etanol sobre el modelo de la DMH en la rata con el fin de evitar la duplicación innecesaria de la experimentación animal o la ejecución de experimentos con animales sin justificación ética en el futuro, además de avisar a los científicos de que los resultados obtenidos de los estudios que han evaluado el etanol con el modelo de la $\mathrm{DMH}$ en la rata no pueden extrapolarse a los seres humanos.
\end{abstract}

Palabras clave: Etanol. Cáncer colorrectal. Dimetilhidrazina. Experimentación animal.

\begin{abstract}
1,2 dimethylhydrazine (DMH) rat model has been proven to be a valuable animal model of colorectal cancer. Because of its morphological similarity to human colorectal cancer, DMH rat model was used to produce information in histology and biochemistry of tumours development as well as on factors that retard or enhance tumorigenesis. Nevertheless, it has been shown that DMH model has limitations, which raise the question, whether experiments evaluating effect of ethanol on DMH model are ethically justified. In this paper authors summarize experimental results evaluating effect of ethanol consumption on DMH rat model with aim to prevent unnecessary duplication of animal experimentation or execution of ethically unjustified animal experiments in the future and to warn scientists that results from studies evaluating ethanol on $\mathrm{DMH}$ rat model can not be generalized to humans.
\end{abstract}

Key words: Ethanol. Colorectal cancer. Dimethylhydrazine. Animal experimentation.

Perše M, Cerar A. Dimethylhydrazine model is not appropriate for evaluating effect of ethanol on colorectal cancer. Rev Esp Enferm Dig 2007; 99: 463-466.

\section{INTRODUCTION}

Epidemiological and experimental studies indicate that environmental and dietary factors are probably important determinants of colorectal cancer (CRC). Among dietary factors alcohol intake has been shown to be associated with an increased risk of CRC (1). A large number of epidemiologic studies have examined the possible association of

Recibido: 23-03-07.

Aceptado: 19-04-07.

Correspondencia: Martina Perše, DVM, Institute of Pathology, Medical Experimental Centre. Medical Faculty. University of Ljubljana. Korytkova 2.1105 Ljubljana, Slovenia.e-mail: martina.perse@mf.uni-lj.si beer and ethanol ingestion on CRC risk. As a result, some epidemiological studies have shown a positive association between alcohol or beer consumption and CRC but the other have not (1-8). Finally, to evaluate the effect of alcohol on CRC under defined experimental conditions experiments on animal models have been performed (9-14).

Recently, Perez-Holanda and co-workers conducted experiment evaluating the effect of ethanol consumption on 1,2 dimethylhydrazine (DMH) rat model to contribute to understanding the conflicting epidemiological results (15). Unfortunately, results of ethanol studies using DMH model are not applicable for comparison of epidemiological results $(6,13,16,17)$. Therefore, we decided to briefly summarize and discuss previous work at that field to emphasize the inappropriateness of DMH rat model in ethanol studies. 
The purpose of our brief paper is thus to prevent unnecessary duplication of animal experimentation or execution of ethically unjustified animal experiments in the future and to warn scientists that results from studies evaluating ethanol on DMH model can not be generalized to humans. After all, we would like to remind researchers, for both ethical and scientific reasons, to consider potential limitations of any animal model before executing experiment.

\section{ETHANOL AND DMH MODEL}

In 1980s, epidemiological studies have shown conflicting correlations between alcohol consumption and incidence of colorectal tumours $(1,4)$. The relationship between beer consumption and rectal cancer has been emphasized in some of these studies $(3,5,8)$. Even today, when the numerous of epidemiological studies evaluating the effect of alcohol on CRC risk have been performed, the results are still debatable $(2,6,7)$.

Since studies using experimental models have the potential to contribute to understanding the conflicting epidemiological data, because make it possible to control all variables that can affect the outcome of the study (18), Pérez Holanda et al. (15) executed experiment on DMH animal model to clarify the effect of ethanol consumption under defined experimental conditions. DMH rat model has been proven to be a valuable animal model of CRC. Because of its morphological similarity to human CRC, DMH rat model has been used to produce information in histology and biochemistry of tumours development as well as on factors that retard or enhance tumorigenesis (19). Nevertheless, it has been also shown that DMH model has limitations $(13,20-23)$, which raise the question, whether experiment executed by Perez-Holanda et al. (15) was ethically justified.

Based on literature DMH model is not appropriate animal model for investigating the effect of ethanol consumption $(13,14,20-23)$.

\section{FIRST ETHANOL STUDIES ON DMH RAT MODEL AND ITS DRAWBACKS}

In 1980s, Howarth et al. (10) have shown that neither beer nor alcohol of equivalent ethanol concentration had any effect on the number of DMH induced adenomas or carcinomas. His results were in part consistent with $\mathrm{Nel}-$ son et al. (12) who have also shown no effect of ethanol on DMH induced tumours but have observed significantly fewer tumours in beer group compared to the control group, suggesting beer protective role on experimentally induced colorectal carcinogenesis (12). Nevertheless, in these studies the food, calorie, ethanol or beer intake of animals, variables that could have affected CRC development, were not controlled.
To exclude effect of uncontrolled food intake and the potential carcinogenic effect of different concentration of diet components and consecutively to allow assessment of ethanol, several scientists used in their ethanol experiments on DMH model pair feeding regimen with isocaloric liquid diets, which had equivalent percent of calories from proteins, carbohydrates and fats $(9,11,14,20,23)$.

\section{STANDARDIZED ETHANOL STUDIES ON DMH MODEL AND CONFLICTING RESULTS}

Hamilton et al. (9) have reported that tumour outcome varied with alcohol dose and anatomic site as well. Rats consuming high ethanol diets $(23 \%$ of total calories as ethanol in both the beer and ethanol group) developed significantly reduced incidence of tumours in the ascending and transverse colon. Meanwhile, no difference from control in tumour incidence in experimental groups of low ethanol diets $(11 \%$ of total calories as ethanol in the beer and ethanol group) was found (9). In contrast, Seitz and co-workers have reported that chronic ethanol administration in DMH treated rats increased total number of tumours in the last $5 \mathrm{~cm}$ of the large intestine, where the 2,8-fold increase in the number of tumours have been observed compared with the control group. No carcinogenic effect of ethanol was observed in other parts of intestine. Likewise, chronic ethanol consumption did not influence tumour size nor tumour histology (14). Also McGarrity et al. (11), who used a similar protocol regarding diet, animals and DMH administration as Seitz et al. (14) but different schedule and the number of animals sacrificed, have reported that chronic ethanol consumption have shown trend toward increased formation of DMH induced tumours in the descending colon (11). In contrast to Seitz et al. (14), McGarrity et al. (11) have also observed trend toward decreased number of tumours in the ascending and transverse colon. However, the number of animals and consecutively the number of tumours was too small to find statistically significant differences (11).

\section{THE EFFECT OF ETHANOL CONSUMPTION ON DMH MODEL}

As shown, studies on DMH rat model varied in the timing of ethanol diet administration relative to carcinogen administration and also in the quantity of ethanol consumed. To evaluate these two factors another study on the AOM treated rats was performed (20). It has been shown that dietary ethanol inhibits, tumorigenesis when given before and during carcinogen administration but has no effect on tumorigenesis when given after carcinogen administration. Surprisingly, the results have shown that colonic tumour incidence was reduced in both the 
$22 \%$ and $33 \%$ ethanol diet groups as compared to control. When administered in high levels (33\% of calories, about $70 \mathrm{~g}$ of ethanol/kg body weight/wk) marked suppression of tumorigenesis occurred, but at low levels of ethanol consumption (11\% of calories, about $20 \mathrm{~g}$ of ethanol $/ \mathrm{kg}$ body weight/wk) no inhibition of tumorigenesis has been found (20). Finally, it was confirmed that both the time of ethanol diet administration and the quantity of ethanol consumed were important factors in DMH or AOM induced colorectal carcinogenesis (20).

In the light of these findings it becomes clear, why studies evaluating the effect of ethanol on DMH model by different researchers with different experimental design have shown controversial results. Regarding ethanol administration relevant to carcinogen administration ethanol studies on DMH model can be divided into studies with concomitant and separate ethanol administration.

Most researches executed experiment with concomitant administration of ethanol and carcinogen $(9,10,12$, $15,20)$. Considering above described findings (20) it is obvious that the quantity of ethanol consumed in study by Perez-Holanda et al. (15) was too low $(1,23 \mathrm{~g} / \mathrm{kg}$ per day added to the drinking water) to modify DMH induced colorectal tumorigenesis. It is likely that also in study by Howarth et al. (10) and Nelson et al. (12) the quantity of ethanol consumed was too low to affect tumour outcome. With the exception of one experiment, where beer intake was not measured and significant reduction in number of tumours has occurred (12). Since rats were given beer as a sole drinking fluid, we can speculate that rats had consumed high amount of beer and consequently high levels of ethanol, which affected tumour outcome. For, it has been observed that the number of colonic tumours is inversely correlated with ethanol consumption $(9,20)$.

On the other side separate ethanol administration was used in experiments executed by Seitz (14) and McGarrity (11). Although in these two studies ethanol intake was high $(36 \%$ of total calories as ethanol) the number of tumours was not reduced (11), as might be expected, but was even increased (14). The results seem at first in contrast to Hamilton $(9,20)$, but according to special experimental design (ethanol diets were omitted for 4 weeks during DMH administration), we can speculate that the total amount of ethanol consumed was too small and interaction of carcinogen activation by ethanol have been avoided.

\section{ETHANOL HAS INFLUENCE ON THE ACTIVATION OF CARCINOGEN}

Since liver microsomes are involved in metabolism of DMH or AOM, their activity can be one of the indicators of the metabolism of DMH or AOM. It has been shown that liver microsomes obtained from both rats fed the continuous ethanol diet and interrupted ethanol diet (in- terrupted for 0.5 day before rats were sacrificed) enhance the metabolism of AOM compared to the control (21). But, although enhanced activity of liver microsomes for carcinogen metabolism is observed in vitro, DNA methylation of liver is not increased in vivo (22). Moreover, DNA methylation in the colon mucosa of rats consuming ethanol is significantly inhibited, indicating that the inhibition is much more pronounced in the colon mucosa (22). After all, Fiala and co-workers have shown that ethanol is competitive inhibitor of the metabolism of carcinogen (22).

\section{DMH MODEL IS NOT APPROPRIATE MODEL FOR ALCOHOL STUDIES}

DMH and its metabolite AOM are highly specific carcinogens for colonic epithelium and induce tumours mostly in large bowel $(24,25)$. The tumour incidence can be modulated by the amount of carcinogen administered and the number of applications. With the increasing doses of the carcinogen, the latency period decreases and the tumour incidence increases $(19,24,25)$. One characteristic of high dose of carcinogen is also induction of small bowel tumorigenesis (23). But in case of high ethanol consumption tumorigenesis in the small and large bowel of high dose of carcinogen is inhibited dramatically, which regarding above described findings clearly demonstrate that DMH model is not relevant model for comparison with epidemiological results evaluating effects of alcohol consumption (23).

\section{GENETIC MODELS}

Today, we have more appropriate animal models of CRC, where induction of carcinogenesis with potential interference with ethanol is avoided (26). Recently, Roy et al. (13) executed experiment on Min mouse, which is one of the genetic models of CRC, to assess the effect of ethanol on colon carcinogenesis without interfering of carcinogen. After all, it was demonstrated on more appropriate animal model that ethanol consumption has affected intestinal tumorigenesis and suggested that ethanol consumption is a risk factor for CRC (13).

\section{CONCLUSIONS}

Studies on different animal models of CRC are needed to explore various aspects of CRC and to provide full understanding of the role of various substances that cause CRC. They also allow a systematic evaluation of the growth, morphologic, cellular and molecular features of tumour lesions under defined experimental conditions because makes it possible to monitor events by examining the dissected colons of randomly selected animals 
from a group, at different time intervals, as the disease progresses. But at the same time it is equally important to understand the limitations of individual animal model. It is understandable that the results of inappropriate animal model are questionable from the scientific and ethical point of view and are mostly useless.

European Union has published Directive 86/609/EEC in 1986 about the careful and responsible way we should use the animals in science. Directive 86/609/EEC obligates the scientists before executing experiment to weigh the benefits of the experiment against animal suffering and to check whether suffering is kept to an absolute minimum and whether no alternative methods can be used. Therefore, for both ethical and scientific reasons, we would like to remind researchers that searching for literature is very important unavoidable task, which should be done before designing an experiment. Although it is time consuming should be carried out carefully and responsibly, because it is the only guarantee of responsible and ethically justified use of animals in experiments.

\section{REFERENCES}

1. Potter JD, McMichael AJ. Diet and cancer of the colon and rectum: A case-control study. J Natl Cancer Inst 1986; 76: 557-69.

2. Akhter M, Kuriyama S, Nakaya N, Shimazu T, Ohmori K, Nishino Y, et al. Alcohol consumption is associated with an increased risk of distal colon and rectal cancer in Japanese men: The Miyagi Cohort Study. Eur J Cancer 2007; 43: 383-90.

3. Enstrom JE. Colorectal cancer and beer drinking. Br J Cancer 1977; 35: 674-83.

4. Gerhardsson DV, Romelsjo A, Lundberg M. Alcohol and cancer of the colon and rectum. Eur J Cancer Prev 1993, 2: 401-8.

5. Goldbohm RA, van den Brandt PA, van't Veer P, Brants HA, Dorant E, Sturmans F, Hermus RJ. Prospective study on alcohol consumption and the risk of cancer of the colon and rectum in the Netherlands. Cancer Causes Control 1994; 5: 95-104.

6. Moskal A, Norat T, Ferrari P, Riboli E. Alcohol intake and colorectal cancer risk: A dose-response meta-analysis of published cohort studies. Int J Cancer 2007; 120: 664-71.

7. Pedersen A, Johansen C, Gronbaek M. Relations between amount and type of alcohol and colon and rectal cancer in a Danish population based cohort study. Gut 2003; 52: 861-7.

8. Riboli E, Cornee J, quart-Moulin G, Kaaks R, Casagrande C, Guyader M. Cancer and polyps of the colorectum and lifetime consumption of beer and other alcoholic beverages. Am J Epidemiol 1991; 134: 157-66.

9. Hamilton SR, Hyland J, McAvinchey D, Chaudhry Y, Hartka L, Kim HT, et al. Effects of chronic dietary beer and ethanol consumption on experimental colonic carcinogenesis by azoxymethane in rats. Cancer
Res 1987; 47: 1551-9.

10. Howarth AE, Pihl E. High-fat diet promotes and causes distal shift of experimental rat colonic cancer-beer and alcohol do not. Nutr Cancer 1984; 6: 229-35.

11. McGarrity TJ, Peiffer LP, Colony PC, Pegg AE. The effects of chronic ethanol administration on polyamine content during dimethylhydrazine-induced colorectal carcinogenesis in the rat. Carcinogenesis 1988; 9: 2093-8.

12. Nelson RL, Samelson SL. Neither dietary ethanol nor beer augments experimental colon carcinogenesis in rats. Dis Colon Rectum 1985; 28: 460-2.

13. Roy HK, Gulizia JM, Karolski WJ, Ratashak A, Sorrell MF, Tuma D. Ethanol promotes intestinal tumorigenesis in the MIN mouse. Multiple intestinal neoplasia. Cancer Epidemiol Biomarkers Prev 2002; 11 : 1499-502.

14. Seitz HK, Czygan P, Waldherr R, Veith S, Raedsch R, Kassmodel H, Kommerell B. Enhancement of 1,2-dimethylhydrazine-induced rectal carcinogenesis following chronic ethanol consumption in the rat. Gastroenterology 1984; 86: 886-91.

15. Pérez Holanda S, Rodrigo L, Vinas-Salas J, Pinol Felis C. Effect of ethanol consumption on colon cancer in an experimental model. Rev Esp Enferm Dig 2005; 97: 87-96.

16. Choi SW, Stickel F, Baik HW, Kim YI, Seitz HK, Mason JB. Chronic alcohol consumption induces genomic but not p53-specific DNA hypomethylation in rat colon. J Nutr 1999; 129: 1945-50.

17. Simanowski UA, Stickel F, Maier H, Gartner U, Seitz HK. Effect of alcohol on gastrointestinal cell regeneration as a possible mechanism in alcohol-associated carcinogenesis. Alcohol 1995; 12: 111-5.

18. Festing MFW, Overend P, Gaines Das G, Borja MC, Berdoy M. The design of animal experiments. London: The Royal Society of Medicine Press Limited; 2004.

19. Perse M, Cerar A. The dimethylhydrazine induced colorectal tumours in rat-experimental colorectal carcinogenesis. Radiol Oncol 2005; 39: 61-70.

20. Hamilton SR, Sohn OS, Fiala ES. Effects of timing and quantity of chronic dietary ethanol consumption on azoxymethane-induced colonic carcinogenesis and azoxymethane metabolism in Fischer 344 rats. Cancer Res 1987; 47: 4305-11.

21. Sohn OS, Fiala ES, Puz C, Hamilton SR, Williams GM. Enhancement of rat liver microsomal metabolism of azoxymethane to methylazoxymethanol by chronic ethanol administration: Similarity to the microsomal metabolism of $\mathrm{N}$-nitrosodimethylamine. Cancer Res 1987; 47: 3123-9.

22. Fiala ES, Sohn OS, Hamilton SR. Effects of chronic dietary ethanol on in vivo and in vitro metabolism of methylazoxymethanol and on methylazoxymethanol-induced DNA methylation in rat colon and liver. Cancer Res 1987; 47: 5939-43.

23. Hamilton SR, Sohn OS, Fiala ES. Inhibition by dietary ethanol of experimental colonic carcinogenesis induced by high-dose azoxymethane in F344 rats. Cancer Res 1988; 48: 3313-8.

24. Shirai T, Nakanowatari J, Kurata Y, Fukushima S, Ito N. Different dose-response relationships in the induction of different types of colonic tumors in Wistar rats by 1,2-dimethylhydrazine. Gann 1983; 74: $21-7$.

25. Sunter JP, Appleton DR, Wright NA, Watson AJ. Pathological features of the colonic tumours induced in rats by the administration of 1,2-dimethylhydrazine. Virchows Arch B Cell Pathol 1978; 29: 211 23.

26. Banerjee A, Quirke P. Experimental models of colorectal cancer. Dis Colon Rectum 1998; 41: 490-505. 